\title{
Size Optimization of Asphalt Particles for Profile Control in Lamadian
}

\section{Oilfield P Reservoir}

\author{
Guang Sheng Cao ${ }^{1, \text { a }}$, Yu Jie Bai ${ }^{1, \mathrm{~b}}$, Xin $\mathrm{Li}^{1, \mathrm{c}}$, Zhong He Zhou ${ }^{2, \mathrm{~d}}$, \\ Cheng Feng $\operatorname{Ren}^{2, \mathrm{e}}$, Ze $\mathrm{Li}^{1, \mathrm{f}}$ and Chun Cheng $\mathrm{Li}^{1, \mathrm{~g}}$ \\ ${ }^{1}$ Key Laboratory of Enhanced Oil and Gas Recovery Ministry of Education, Northeast Petroleum \\ University, Daqing China, 163318 \\ 2.The Sixth Production Plant of Daqing Oil Field Co., LTD,Daqing China, 163114 \\ ${ }^{a}$ caoguangsheng@163.com, b1414190195@qq.com, \\ '674785398@qq.com, ${ }^{\mathrm{d}} z$ houzhonghe@petrochina.com.cn, ${ }^{\mathrm{e}}$ renchengfeng@petrochina.com.cn, \\ f458599205@qq.com, ${ }^{\mathrm{g}} 349610362 @ q q . c o m$
}

\begin{abstract}
Keywords: Asphalt particle; Profile control; Particle size optimization; Improve recovery efficiency
\end{abstract}

\begin{abstract}
The exploitation of Lamadian oil field P layer has been in the ultra-high water stage, there is a serious inefficient circulation of injected water. Low cost asphalt particle profile control technology has been researched and carried out in this reservoir. While, there is still no guidance for size-selection of asphalt particles in application. In this paper, based on simulation profile control experiment in laboratory, using three layer heterogeneous cores with rectangle conducting section, the asphalt particle size had been selected under two kinds of injection rate to match different permeability formation. At the same time, the scour resistance of asphalt particle was evaluated. This paper illusrates that different permeability cores can be injected different particle size limit: $0.06 \mathrm{~mm}$ asphalt particle can be injected into $500 \times 10^{-3} \mu \mathrm{m}^{2}$ permeability core; $0.1 \mathrm{~mm}$ asphalt particle can be injected into $1500 \times 10^{-3} \mu^{2}$ permeability core; $0.3 \mathrm{~mm}$ asphalt particle can be injected into $3000 \times 10^{-3} \mu \mathrm{m}^{2}$ permeability core. The bigger the size of asphalt particle, the greater the resistance to scour.
\end{abstract}

\section{Intrduction}

Profile control technology is a kind of stimulation widely used in middle and later periods of the oil field. Carrying on profile control in high water cut stage of oil field development, not only can adjust the interlayer contradiction, enlarge sweep volume, but also can improve efficiency of oil displacement. Aiquid profile control agent has obtained certain effect in practical application, particle profile control agent has obvious advantages of blocking big channel. Recent years, asphalt particle profile control agent has been paid more attention by oil field workers, because of its characteristics, including its low cost, strong adaptability and small reservoir damage and so on.

Because asphalt profile control agent is possessed of some good properties, such as mechanical blockage effect, bonding at high temperatures $\left(>40^{\circ} \mathrm{C}\right)$, it could detain in different depth strata, to achieve high strength of plugging, and force subsequent injection water into low and middle permeability reservoir which is unswept, to make the diversion of flow in the reservoir, and increase the swept volume coefficient of injected water, and improve the oil recovery efficiency. Asphalt 
particles were transnatured by Renchengfeng [1], Gaobo [2] and other researchers also evaluated the suspension of asphalt particles after being transnatured. New type piston pump was developed by Mohan [3] to inject asphalt particles, that solved a high pressure injection technical puzzle. But there is still a matching problem between asphalt particle size and reservoir property, and injection system. Therefore, it is necessary to optimize the asphalt particle profile size.

\section{Reservoir physical properties of P layer inLamadian oil field}

P layer,the main reservoir in Lamadian oil field [4], is serious heterogeneity after long-term water injecting. Some layers are flooded seriously, the contradiction between layers is outstanding. There are three kinds of layers with bigger effective thick, their permeability are: $500 \times 10^{-3} \mu \mathrm{m}^{2}$, $1500 \times 10^{-3} \mu \mathrm{m}^{2}, 3000 \times 10^{-3} \mu \mathrm{m}^{2}$.

\section{Asphalt particle size optimization}

Experimental scheme. Profile control solution with asphalt particles were compounding (the diameter of these particles: $0.02 \mathrm{~mm}$ to $0.8 \mathrm{~mm}$ ), under the condition of $Q=3 \mathrm{~mL} / \mathrm{min}, 0.2 \mathrm{PV}$ asphalt particle profile control solution was injected into the cores which saturated by oil, then, the core permeability, resistance coefficient and residual resistance coefficient [5] were measured, the plugging rate $(E)$ was calculated (refer with Eq. 1).

$$
E=\frac{K_{1}-K_{2}}{K_{1}} \times 100 \%
$$

where, $K_{1}$ is the initial permeability of core, $K_{2}$ is the permeability of core after asphalt particle profile control solution was injected.

Experimental results. Using asphalt particles of 5 kinds of size $(0.02 \mathrm{~mm} 、 0.02-0.06 \mathrm{~mm}$,

$0.06-0.1 \mathrm{~mm} 、 0.1-0.3 \mathrm{~mm} 、 0.3-0.8 \mathrm{~mm}$ ), the profile control solutions (concentration: $3500 \mathrm{mg} / \mathrm{L}$ ) were prepared. Under the condition of flow rate of $3 \mathrm{~mL} / \mathrm{min}, 0.2 \mathrm{PV}$ the solution of profile control agent was injected into the core. The experimental data was shown in Table1, Table 2, Table3.

Table 1 The experimental data (the core permeability is about $500 \times 10^{-3} \mu^{2}$ )

\begin{tabular}{c|c|c|c|c|c|c|c}
\hline $\begin{array}{c}\text { Particle } \\
\text { size } \\
{[\mathrm{mm}]}\end{array}$ & $\begin{array}{c}\text { Core } \\
\text { number }\end{array}$ & $\begin{array}{c}K_{1} \\
{\left[10^{-3} \mu \mathrm{m}^{2}\right]}\end{array}$ & $\begin{array}{c}K_{2} \\
{\left[10^{-3} \mu \mathrm{m}^{2}\right]}\end{array}$ & $\begin{array}{c}\text { Resistance } \\
\text { coefficient }\end{array}$ & $\begin{array}{c}\text { Residual } \\
\text { resistance } \\
\text { factor }\end{array}$ & $\begin{array}{c}\text { Plugging } \\
\text { ratio } \\
{[\%]}\end{array}$ & $\begin{array}{c}\text { Improved } \\
\text { recovery } \\
\text { efficiency[\%] }\end{array}$ \\
\hline \multirow{2}{*}{0.02} & $1 \#$ & 514 & 139 & 29.92 & 3.70 & 73 & 12.54 \\
\cline { 2 - 8 } & $2 \#$ & 529 & 158 & 27.09 & 3.35 & 70 & 11.68 \\
\hline \multirow{2}{*}{$0.02-0.06$} & $1 \#$ & 516 & 124 & 33.67 & 4.16 & 76 & 12.89 \\
\cline { 2 - 8 } & $2 \#$ & 508 & 116 & 35.43 & 4.38 & 77 & 13.07 \\
\hline \multirow{2}{*}{$0.06-0.1$} & $1 \#$ & 514 & 51 & - & - & - & - \\
\cline { 2 - 8 } & $2 \#$ & 495 & 53 & - & - & - & - \\
\hline
\end{tabular}


Table 2 The experimental data (the core permeability is about $1500 \times 10^{-3} \mu^{2}$ )

\begin{tabular}{|c|c|c|c|c|c|c|c|}
\hline $\begin{array}{c}\text { Particle } \\
\text { size } \\
{[\mathrm{mm}]}\end{array}$ & $\begin{array}{c}\text { Core } \\
\text { number }\end{array}$ & $\begin{array}{c}K_{1} \\
{\left[10^{-3} \mu \mathrm{m}^{2}\right]}\end{array}$ & $\begin{array}{c}K_{2} \\
{\left[10^{-3} \mu \mathrm{m}^{2}\right]}\end{array}$ & $\begin{array}{l}\text { Resistance } \\
\text { coefficient }\end{array}$ & $\begin{array}{c}\text { Residual } \\
\text { resistance } \\
\text { factor }\end{array}$ & $\begin{array}{c}\text { Plugging } \\
\text { ratio } \\
{[\%]}\end{array}$ & $\begin{array}{c}\text { Improved } \\
\text { recovery } \\
\text { efficiency[\%] }\end{array}$ \\
\hline \multirow{2}{*}{0.02} & $1 \#$ & 1575 & 720 & 17.70 & 2.19 & 54 & 11.36 \\
\hline & 2\# & 1502 & 760 & 15.99 & 1.98 & 49 & 10.98 \\
\hline \multirow{2}{*}{$0.02-0.06$} & $1 \#$ & 1591 & 610 & 21.10 & 2.61 & 62 & 14.68 \\
\hline & $2 \#$ & 1482 & 582 & 20.60 & 2.55 & 61 & 15.95 \\
\hline \multirow{2}{*}{$0.06-0.1$} & $1 \#$ & 1484 & 556 & 21.59 & 2.67 & 63 & 16.67 \\
\hline & 2\# & 1570 & 568 & 22.36 & 2.76 & 64 & 16.26 \\
\hline \multirow{2}{*}{$0.1-0.3$} & $1 \#$ & 1515 & 165 & - & - & - & - \\
\hline & $2 \#$ & 1491 & 158 & - & - & - & - \\
\hline
\end{tabular}

Table 3 The experimental data (the core permeability is about $3000 \times 10^{-3} \mathrm{~mm}^{2}$ )

\begin{tabular}{c|c|c|c|c|c|c|c}
\hline $\begin{array}{c}\text { Particle } \\
\text { size } \\
{[\mathrm{mm}]}\end{array}$ & $\begin{array}{c}\text { Core } \\
\text { number }\end{array}$ & $\begin{array}{c}K_{1} \\
{\left[10^{-3} \mu \mathrm{m}^{2}\right]}\end{array}$ & $\begin{array}{c}K_{2} \\
{\left[10^{-3} \mu \mathrm{m}^{2}\right]}\end{array}$ & $\begin{array}{c}\text { Resistance } \\
\text { coefficient }\end{array}$ & $\begin{array}{c}\text { Residual } \\
\text { resistance } \\
\text { factor }\end{array}$ & $\begin{array}{c}\text { Plugging } \\
\text { ratio } \\
{[\%]}\end{array}$ & $\begin{array}{c}\text { Improved } \\
\text { recovery } \\
\text { efficiency[\%] }\end{array}$ \\
\hline \multirow{2}{*}{0.02} & $1 \#$ & 3012 & 1325 & 18.39 & 2.27 & 56 & 9.90 \\
\cline { 2 - 8 } & $2 \#$ & 2994 & 1175 & 20.62 & 2.55 & 61 & 9.77 \\
\hline $0.02-0.0$ & $1 \#$ & 3042 & 1100 & 22.37 & 2.77 & 64 & 10.96 \\
\cline { 2 - 8 } 6 & $2 \#$ & 2991 & 1046 & 23.13 & 2.86 & 65 & 10.06 \\
\hline \multirow{2}{*}{$0.06-0.1$} & $1 \#$ & 3011 & 1075 & 22.66 & 2.80 & 64 & 11.02 \\
\cline { 2 - 8 } & $2 \#$ & 3021 & 954 & 25.62 & 3.17 & 68 & 11.95 \\
\hline \multirow{2}{*}{$0.1-0.3$} & $1 \#$ & 2991 & 993 & 25.99 & 3.21 & 69 & 11.34 \\
\cline { 2 - 8 } & $2 \#$ & 3024 & 986 & 27.29 & 3.37 & 70 & 11.78 \\
\hline \multirow{2}{*}{$0.3-0.8$} & $1 \#$ & 2987 & 625 & - & - & - & - \\
\cline { 2 - 8 } & $2 \#$ & 3048 & 582 & - & - & - & - \\
\hline
\end{tabular}

It can be illustrated from Table 1 to Table 3: the cores whose permeability is about $500 \times 10^{-3} \mu \mathrm{m}^{2}$ can be injected by $0.02 \mathrm{~mm}$ and $0.02-0.06 \mathrm{~mm}$ asphalt particle. the cores whose permeability is about $1500 \times 10^{-3} \mu^{2}$ can be injected by $0.02 \mathrm{~mm}, 0.02-0.06 \mathrm{~mm} 0.06-0.1 \mathrm{~mm}$ asphalt particle. he cores whose permeability is about $3000 \times 10^{-3} \mu \mathrm{m}^{2}$ can be injected by $0.02 \mathrm{~mm}, 0.02-0.06 \mathrm{~mm}, 0.06-0.1 \mathrm{~mm}$ and $0.1-0.3 \mathrm{~mm}$ asphalt particle. From analyzing on the result, we can see that, with the size of asphalt particle increasing, the increase amplitude of EOR will enlarge.

Each table has a phenomenon that the permeability gets smaller suddenly after the large asphalt particles are injected. The reason is that the particle size is too big to be injected into the core deeply, and gathers on the end face seriously (shown in Fig.1).

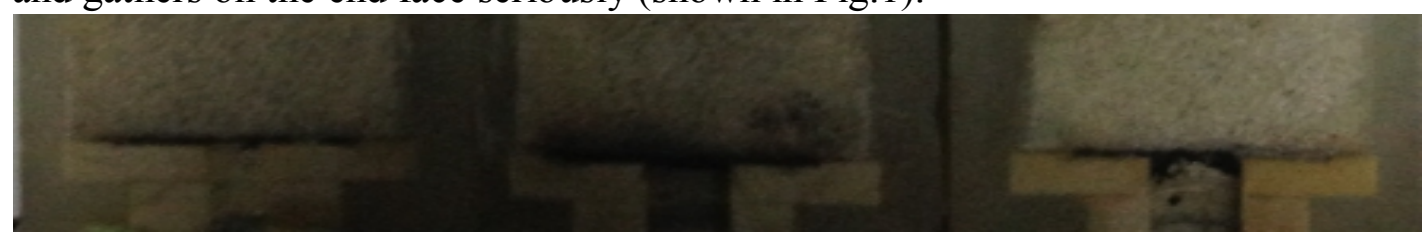

Fig.1 Gathering of asphalt particles on the end face 
Based on the analysis above, the matching relationship between size of asphalt particles with permeability of core was built up (refer with Table 4).

Table 4 The matching relationship between size of asphalt particles with permeability of core

\begin{tabular}{c|c|c}
\hline Permeability $\left[10^{-3} \mu^{2}\right]$ & Passable particle size $[\mathrm{mm}]$ & The best size $[\mathrm{mm}]$ \\
\hline 500 & $0.02,0.02-0.06$ & $0.02-0.06$ \\
\hline 1500 & $0.02 、 0.02-0.06,0.06-0.1$ & $0.06-0.1$ \\
\hline 3000 & $0.02 、 0.02-0.06,0.06-0.1,0.1-0.3$ & $0.1-0.3$ \\
\hline
\end{tabular}

Because that formation heterogeneity is serious, large size asphalt particles $(0.3-0.8 \mathrm{~mm})$ are difficult to be injected, they will gather in the zone near wellbore, the small size asphalt particles $(0.02 \mathrm{~mm})$ can't plug high permeable zone very well. Thus, it is necessary to use the mixture compounded asphalt particles with different sizes for plugging the channel with different sizes.

\section{Asphalt particle's washout resistance experiment}

In this experiment, three-layer inhomogeneous core with conducting section $(4.5 \mathrm{~cm} \times 4.5 \mathrm{~cm} \times 30 \mathrm{~cm})$ was used, and the profile control solution of $3500 \mathrm{mg} / \mathrm{L}$ was prepared with four sizes of asphalt particles $(0.02 \mathrm{~mm}, 0.02-0.06 \mathrm{~mm}, 0.06-0.1 \mathrm{~mm}, 0.1-0.3 \mathrm{~mm})$. Under the constant flow of $Q=3 \mathrm{~mL} / \mathrm{min}, 0.2 \mathrm{PV}$ of asphalt particles profile control solution was injected into the three-layer inhomogeneous core, then water was injected subsequently. Based on the experiment above,washout resistance can be evaluated. After asphalt particles was injected, With the increase of water volume injected, the core's permeability increases (refer with Fig. 2).

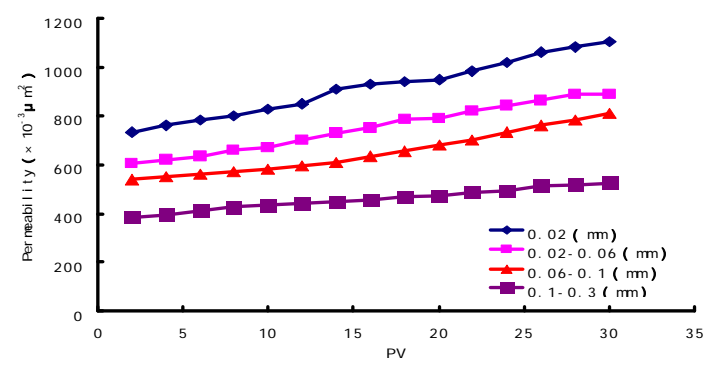

Fig. 2 Asphalt particle's washout resistance

From Fig. 2 above we can know, with the increase of the PV of water injected, at beginning, there is a permeability rising trend. For the cores injected with $0.02 \mathrm{~mm}, 0.02-0.06 \mathrm{~mm}, 0.06-0.1$ $\mathrm{mm}$ asphalt particles, with the increase of the injected water PV value, the increase amplitude of permeability is larger. Otherwise, for the core injected with $0.1-0.3 \mathrm{~mm}$ asphalt particles, as the increase of the injected water PV value, the increase amplitude of permeability is smaller. So, the greater size of asphalt particles injected, the better washout resistance.

\section{Summary}

1. The matching relationship between the size of asphalt particles and the formation permeability was determined: the cores whose permeability is about $500 \times 10^{-3} \mu \mathrm{m}^{2}$ can be injected by $0.02 \mathrm{~mm}$ 
and $0.02-0.06 \mathrm{~mm}$ asphalt particles; the cores whose permeability is about $1500 \times 10^{-3} \mu \mathrm{m}^{2}$ can be injected by $0.02 \mathrm{~mm}, 0.02-0.06 \mathrm{~mm}$ and $0.06-0.1 \mathrm{~mm}$ asphalt particles; the cores whose permeability is about $3000 \times 10^{-3} \mu \mathrm{m}^{2}$ can be injected by $0.02 \mathrm{~mm}, 0.02-0.06 \mathrm{~mm}, 0.06-0.1 \mathrm{~mm}$ and $0.1-0.3 \mathrm{~mm}$ asphalt particles.

2. The effect of control profile using $0.1-0.3 \mathrm{~mm}$ or $0.06-0.1 \mathrm{~mm}$ asphalt particles is better than using $0.02 \mathrm{~mm}$ or $0.02-0.06 \mathrm{~mm}$ asphalt particles. On the premise that asphalt particles can be injected into core, the greater size of asphalt particles, the better washout resistance.

\section{References}

[1] Cheng Feng Ren, "Profile control technology of low-cost bitumen particles in Lamadian oilfield", Journal of Northeast Petroleum University, Vol. 38(3) (2014), p. 81-86

[2] Han Mo, "A spot test study on injection profile modification with asphalt grain", Thesis for the graduate candidate test, 2008

[3] Bo Gao, "Research on Pressure Drop Interpretation in the Stage of Stewing in Steam Soak of Heavy oil Recovery", Petroleum Geology\&OilField Development in Daqing, Vol. 04(2006), p. 96-97,125

[4] Chun Yan Zhang, "Research on determining reservoir classification method in Lamadian oil field", China Petroleum and Chemical Standard and Quality, 2012

[5] Jie Cheng Cheng, Mei Shi, Xiu Lan Gao, "Effect on resistance factor and residual resistance factor for polymer solution flow through porous media", Journal of Daqing Petroleum Institute, Vol. 03(1992), p. 31-36 